\title{
VISIÓN INTERDISCIPLINARIA DE LA FAMILIA ${ }^{1}$
}

\section{Ángela María Quintero Velásquez ${ }^{2}$}

\section{Resumen}

El artículo expone una aproximación a la concepción moderna de Familia, dando cuenta de la necesaria convergencia entre las ciencias clásicas y los enfoques actuales que postulan y tratan a la familia del tercer milenio. Para ello se debe tener en cuenta la antropología, la psicología, el psicoanálisis, la sociología, la teoría general de sistemas, el interaccionismo simbólico, el construccionismo social, la cibernética y el pensamiento complejo, entre otros. Enfatiza los enlaces con el derecho, en tanto marco legal y jurídico y cumplimiento de las constituciones. Expresa el cambio de paradigma con la nueva comprensión y abordaje de la Familia, de manera integral y holística.

Descriptores: familia, interdisciplinariedad, paradigma, ciencias sociales, derechos, sistema.

\section{Abstract}

This article presents an approximation to the modern conception of Family, taking into consideration the convergence of the classical sciences with the current approaches dealing with the family of the third millennium. Insights considered come from anthropology, psychology, psychoanalysis, sociology, general systems theory, symbolic interactionism, social constructionism, cybernetics, and complex thought, among others. An emphasis is made on the links with law as a legal and juridical framework and fulfillment of regulations. A change of paradigm is expressed with a new understanding of the family and new ways of approaching it in an integral and holistic way.

\footnotetext{
'Basado en la ponencia presentada en el III Congreso Internacional de Derecho de Familia, Universidad de Antioquia, Medellín, 2006.

${ }^{2}$ Docente Departamento de Trabajo social, Universidad de Antioquia, Medellín, Colombia.
} 
Keywords: family, interdisciplinarity, paradigm, social sciences, law, system.

\section{Introducción}

La Familia, como una institución universal, propia de todas las culturas, es estudiada y abordada bajo una naturaleza eminentemente interdisciplinaria. En razón de su carácter integral, multicausal y diverso, trasciende fronteras y esquemas del pensamiento para dar lugar a estructuras y funciones insospechadas hace pocos años. Asumimos y al mismo tiempo proponemos, a la par con el título que respalda estas líneas, que gran parte de los profesionales, y las organizaciones que trabajan por el desarrollo humano, comparten la premisa básica de que la dimensión planetaria, la mundialización, las relaciones ecosistémicas y las redes de todo tipo, conllevan gestiones articuladas y colaborativas, para estudiar, evaluar e intervenir a los sistemas humanos, sean individuos, familias, grupos, comunidades o corporaciones. En razón de lo cual, el contenido del texto tratará primero unas nociones básicas de la interdisciplinariedad, luego enuncia los fundamentos científicos del análisis moderno de la familia y concluye con unas provocaciones, sobre la necesaria alianza entre las ciencias sociales y jurídicas, para dar cuenta de la complejidad de las Familias contemporáneas.

Los cambios del tercer milenio, que impactan a toda la comunidad planetaria, exigen una innovación en las estrategias metodológicas y en la cosmosvión del mundo para analizar, comprender e interactuar con la familia. No basta con la atención en situaciones coyunturales $e$ inmediatistas, ni en las contingencias, sino que es menester implementar programas preventivos, promocionales y educativos, que comprometan a organismos gubernamentales y no gubernamentales, al sector privado, a la sociedad civil y toda la ciudadanía. Ya la Familia no es del ámbito privado, sino que circula con solvencia por lo público y puede ser confrontada y replanteada, desde diferentes ámbitos.

Esta categoría es la propuesta que debe ser asumida por los profesionales e instituciones, que de una u otra manera están vinculadas 
con la familia y cada uno de sus miembros. En términos del enfoque de Derechos es reconocer la familia como sujeto prevalente, que para efectos del discurso social, es ser considerada como sujeto de derechos, como protagonista ciudadana, con desarrollos y propuestas acordes a sus cambios estructurales, funcionales y vitales. Pero necesariamente todo ello acorde en una Visión Interdisciplinaria, que integre las ciencias, las disciplinas y los enfoques, clásicos y modernos, que consideran a la Familia y a sus integrantes, como objeto de investigación científica, privilegiando los procedimientos cualitativos.

Como uno de los tantos ejemplos sobre este crecimiento exponencial de la familia en las últimas décadas y su reconocimiento en diferentes contextos, se ilustra la referencia de un estudio interinstitucional de algunas entidades estatales colombianas focalizadas en las nuevas realidades sociales. El Departamento Nacional de Planeación et al, (2002) señala:

Las familias colombianas han sido estudiadas principalmente por los demógrafos y antropólogos. Los trabajadores sociales han escrito poco pero han hecho mucho. Incluso, los abogados de familia son parte del bagaje de conocimiento sobre las familias, ya que han tenido el monopolio de la regulación sobre las mismas [subrayado personal]. La aproximación de la economía al estudio de la familia se ha dado desde dos perspectivas....la familia como unidad de consumo, la generadora de ahorro y oferente de mano de obra...y la segunda trata de entender no sólo los determinantes de los diferentes miembros de la unidad familiar, sino también los procesos a través de los cuales la familia decide.... 


\section{Aproximaciones a la Interdisciplinariedad ${ }^{1}$}

Retomando los avances epistemológicos y metodológicos de las diferentes disciplinas que tienen como su objetivo un área particular del ser humano, es básico el reconocimiento de la interdisciplinariedad, como formulación relativamente nueva en el estudio y comprensión de los fenómenos humanos (Quintero Velázquez, 1995).

En lo fundamental es un acercamiento o puente de unión entre las llamadas Ciencias sociales y humanas o blandas y las Naturales o duras y como postulado conceptual pretende crear un lenguaje común a todas las áreas del conocimiento para abordar de manera integral, holística el objeto de intervención. El desarrollo científico, cuestiona y confronta la creciente especialización y compartamentalización del saber donde la división y fragmentación del conocimiento, también divide y fragmenta el análisis y manejo de la realidad social. Este paradigma, conocido como Analítico, plantea jerarquía en las ciencias, explicación causa-efecto de los fenómenos en una dimensión lineal, reduccionismo y mecanicismo en tanto las cosas se pueden dividir hasta sus últimos elementos, determinismo y aislamiento de una ciencia con respecto a las otras.

Como contrapartida se estructura el paradigma sistémico, donde hay causalidad circular, relaciones complementarias entre las ciencias, probabilismo y expansionismo en los fenómenos, apertura al medio externo. Siendo fundamental la interdisciplinariedad, como una nueva concepción del mundo que sustenta la integración de las ciencias. En su esencia, el nuevo paradigma del conocimiento propone una conceptuación sistémica para comprender y manejar interdisciplinaria e integradamente la complejidad de la realidad social. No es una propuesta nueva, por cuanto sus principios se remontan a los orígenes de la filosofía europea y reivindica la noción de totalidad.

'Consideraciones acerca del trabajo interdisciplinario. En: Prospectiva No 2. Santiago de Cali: Escuela de Trabajo Social y Desarrollo Humano, Facultad de Humanidades. Universidad del Valle, 1995. 
En su acepción más elemental, el término sugiere las relaciones que se establecen entre las ciencias que en niveles, puede variar desde un simple diálogo interdisciplinar, hasta la máxima abstracción posible, o sea a la búsqueda de una metaciencia o metadisciplina englobante sintética de todas las actuales. Sin desconocer el carácter multifacético del llamado triángulo epistemológico: lo natural $=$ Ciencia, lo humano $=$ humanismo y lo sobrenatural $=$ teología $\ldots$ como constituyentes de la realidad humana, la convocatoria a la unión de las ciencias pretende asegurar que la visión global de la realidad se mantenga (Uribe, 1987).

En razón de esta perspectiva es un imposible, una utopía, plantear que una sola área del conocimiento tiene los elementos necesarios para abordar por si sola la complejidad de los procesos socioculturales. En este sentido cada profesión ve de manera aislada, con una visión parcelada, los fenómenos y por más que lo pretenda no consigue estudiar e intervenir la totalidad. Este replanteamiento de las ciencias, no desconoce la necesidad de desarrollos conceptuales y metodológicos específicos, pero si enfatiza el hecho de establecer relaciones entre ellos, que superen la simple coordinación o intercambio profesional. Las tipologías más reconocidas en esta perspectiva son:

* Grupos interprofesionales: es la reunión de individuos formados en un área específica del saber y que desde sus profesiones u oficios aportan en el objeto común del equipo. Sus acciones son coordinadas y hasta participativas pero no implican invasión de límites o asunción de los otros saberes. Son los más frecuentes en el contexto, sobretodo en las áreas de la salud y en los procesos comunitarios, donde no se exige la condición de formación académica para intervenir. Pueden constituirse en el paso previo del equipo interdisciplinario, pero tienen características diferentes.

* Multidisciplinariedad: es la yuxtaposición de varias disciplinas que se unen para abordar un problema, pero 
ello no implica cambio o transformaciones en su saber. Se le conoce también como pluridisciplinariedad o multiprofesional y es un nivel intermedio entre lo interdisciplinario y lo interprofesional.

* Interdisciplinariedad: trasciende la suma de saberes y propone la integración de las disciplinas o ciencias, en torno a objetivos y lenguajes comunes de análisis y abordaje de la realidad.

* Transdisciplinariedad: implica que el contacto y la cooperación entre las diversas disciplinas tienen lugar cuando éstas han terminado por adoptar un mismo método de investigación... el mismo paradigma. (Apostel y otros, 1983). Es un nivel más complejo, que apunta a la definición de una teoría social global, a una visión del mundo. En razón de lo cual su operacionalización es menos viable.

La interdisciplinariedad en su sentido más general, como vocablo que fue acuñado con grafía, a veces descompuesta (interdisciplinariedad), ha merecido múltiples y aún contradictorias acepciones...pero [para lo relevante], baste con significar que ... es la articulación de los distintos saberes de los profesionales de todas las ciencias o disciplinas, que en armonía colaboran y se complementan para contribuir a la obtención de mejores soluciones a los conflictos y problemas sociales, económicos, políticos y familiares en particular, buscando ofrecer alternativas satisfactorias y concretas que respondan a los complejos problemas técnicos y sociales del mundo (Giraldo y otros, 1993). 


\section{Contexto de la familia ${ }^{1}$}

La familia actual carece de certezas, es imprevisible, ello exige estilos de comprensión integradores, dinámicos, flexibles, pero sin dejar el rigor que el examen científico instaura en la Familia, como un asunto de competencia global. Cada familia conserva su particularidad, dentro de lo general. De acuerdo a Quintero Velásquez (2004), los puntos fundamentales para trascender la visión clásica de la Familia, a tono con el cambio de época, son:

- La familia más que estructura es función.

- La cooperación de saberes impone la lógica del trabajo colaborativo y, convergente entre los profesionales, corporaciones y sectores de la sociedad.

- La contundencia de la nuevas organizaciones familiares, requiere asumir posturas y visiones del mundo integradoras, comprensivas, desprovistas de modelos deterministas y lineales. - La interrelación de los procesos individuales, familiares y sociales establece dinámicas flexibles, co-creadoras, integración de dialécticas.

En correspondencia con los tiempos, se asume que el concepto no es unívoco en el hemisferio occidental, en la familia latina no impera un solo modelo: las tipologías clásicas coexisten con las nuevas organizaciones familiares. Las relaciones de la pareja moderna originan diversas transacciones intrafamiliares, sea cualquiera su estructura. La noción de globalización y el deslinde de las fronteras, establece que parte de las características señaladas como propias de una cultura, son observadas en otras latitudes con matizaciones que establecen la diferencia. La tendencia es que las familias expongan elementos relacionales de orden genérico.

' Diversidad familiar en el tercer milenio. (2004). Publicado en: Agora No 4. Medellin: Universidad San Buenaventura, Formación Humana y Bioética. 
Pese al debate e innumerables voces sobre la desintegración, la descomposición o el fin de la familia, está reportado que ella es fuente de protección y seguridad para sus miembros (Departamento Nacional de Planeación, Instituto Colombiano de Bienestar Social, 2002, p 88; CEPAL-NU, 1997, p79; Comité Interinstitucional de Familia, 1999) y como tal sigue cumpliendo dos objetivos básicos: socialización y protección psicoafectiva. La familia como institución no desaparece, es adaptable y mutable según las realidades del contexto, pero se conservará en su cometido vital.

El concepto de familia retoma los principios de las ciencias sociales, jurídicas' y demográficas, formada por mínimo un progenitor con vínculo consanguíneo o civil con la descendencia. Ello abre las expectativas para las nuevas tipologías. La familia como núcleo primario, inćluye la díada parental, los individuos o cada uno de los miembros del sistema y el grupo como una unidad, esto es rescatar la parentalidad, la individualidad y la conyugalidad. En la familia deben generarse espacios para el desarrollo como pareja, persona y grupo social.

La noción de que la familia es un sistema relacional refiere a sus interacciones, sus transacciones intergeneracionales. Pese a que la familia latina tiende a ser tradicional, con predominio de las estructuras clásicas, está replanteando sus mecanismos funcionales. Es una transición para modificar los elementos ideológicos, frente a los patrones proverbiales asignados, y estar a tono con los nuevos escenarios. El sentido de tendencias y contratendencias, permite entender el fenómeno de avanzar hacia lo contemporáneo, a lo reciente pero aún recogiendo lo clásico. De esta manera surgen relaciones más simétricas en la familia, con modelos de

\footnotetext{
'El derecho colombiano, concibe la pareja unida por el matrimonio (civil o religioso), como familia en razón de su parentesco por afinidad, pero para las ciencias sociales modernas la pareja o díada conyugal es un hogar no familiar, con características estructurales, funcionales y vitales diferentes al familia, que implica necesariamente la presencia de un hijo, como evidencia del parentesco por consanguinidad.
} 
comunicación que suscitan variadas opciones de intercambio y expresan el deseo por armonizar los proyectos individuales con los familiares y conyugales. Es propósito ineludible de los científicos y profesionales sociales, analizar a la familia en correspondencia con el fin de la certeza y de las verdades absolutas, para incorporar nuevas narrativas y lecturas de las innovaciones familiares.

\section{Estudio científico de la familia}

Es una premisa común, el afirmar que los conflictos o disfunciones familiares, configuran un problema de tal magnitud que requiere utilizar el máximo de recursos posibles para enfrentarlos. Pero ninguna disciplina por si sola está en capacidad de estudiar y abordar la complejidad de los dilemas humanos. De manera independiente un psicólogo, un sociólogo, un antropólogo, un pedagogo, un trabajador social, un abogado, entre otros no poseen en su repertorio todos los dominios conceptúales o metodológicos, para lograr una atención completa. Es menester una comprensión integral que solo brinda la acción colaborativa entre los campos del saber. Con la premisa planteada inicialmente de que la familia ya es un asunto público y un objeto de estudio e investigación de todas las áreas del conocimiento, se reportan los fundamentos teóricos necesarios para su comprensión moderna y documentada.

Los antecedentes mas reconocidos de los estudios de la familia, son decimonónicos, correspondiendo al surgimiento y consolidación de las Ciencias Sociales y al replanteamiento del orden socio-político mundial, producto de las revoluciones francesa en el siglo XVIII e industrial en Inglaterra, que impactaron al orbe y suscitaron cambios estructurales en las relaciones individuales, familiares y sociales en los dos centurias siguientes. El asumir que el matrimonio o la convivencia de la pareja, puede estar basada en el amor y la pasión, superando las razones pragmáticas o de intereses económicos, políticos o religiosos, que signaron las relaciones conyugales, es un quiebre del orden establecido que instaura, junto con la emergencia y consolidación de la burguesía y el proletariado, nuevos vínculos culturales, personales y familiares. 
Ello es identificado como el Cambio de paradigma, ya que se rompieron los esquemas ideológicos, morales y ciudadanos, para dar lugar a novedosas representaciones y organizaciones. En términos científicos es reconocido como el salto del modelo analítico del conocimiento (reduccionista, determinista, lineal, mecanicista, jerárquico, cartesiano), al modelo sintético (probabilístico, circular, expansionista, sistémico, multidisciplinario), que propugna por la colaboración entre la ciencias y asumir una cosmogonía holística. En razón de lo cual, se reseñan sucintamente, los antecedentes mas relevantes en la comprensión moderna de la Familia.

- Charles Darwin: naturalista británico, creador de la Teoría de la evolución: Origen de las especies.

- Bachofen: (1861) autor alemán propone la noción básica del Derecho Materno, reconocido durante algún tiempo como cimientos de la estructura del matriarcado.

- Federico Engels: filósofo alemán, reconocido en la fundamentación del Materialismo histórico y en su obra clásica sobre el Origen de la Familia, la propiedad privada y el Estado (1884).

- Lewis Morgan: antropólogo norteamericano, investigador de los grupos humanos representativos y los sistemas de parentesco, sobresale su obra La sociedad primitiva, (1878-1970).

Para el siglo XX, los investigadores modernos mas reconocidos sobre la Familia son:

- Claude Lévi-Straus: antropólogo e investigador francés, que entre sus variados temas, estudio las estructuras fundamentales del parentesco y La familia, (1956-1974).

- Murdock: (1968), analizó doscientos cincuenta organizaciones, para concluir el principio de Universalidad de la Familia y la Familia nuclear como entidad universal.

- Talcott Parsons: Sociólogo americano del enfoque estructuralista, pionero en presentar el concepto de la 
- Familia como Sistema Social, Releva en toda su producción la primacía de la familia nuclear, con una postura conservadora del statu-quo.

- Kurt Lewin: familia como campo interpersonal, influencia del orden de hermanos, la composición familiar y la interdependencia de los esposos.

En este orden de ideas las Ciencias clásicas que investigan la Familia, hacia el Siglo XIX y XX, son:

- Antropología: filiación, alianza y sistemas de parentesco. La cultura como fundamento de las organizaciones humanas.

- Historia: evolución social y cultural, en contextos.

- Psicología: los grupos primarios son principales agentes socialización, procesos internos y subjetivos en familia. Interacción familiar. Grupo pequeño en interacción. Psicología social

- Psicoanálisis: influencia de Sigmund Freud. Fundamentó conceptos como, El estudio psicoanalítico de la familia. Rivalidad entre hermanos. Dos interacciones padres-hijos.

- Sociología: estructura y funciones, relaciones externas de la familia con la sociedad.

- Interaccionismo simbólico: las personas no nacen con un sentido de si mismas, sino que desarrollan conceptos a través de la interacción social. Identidad, roles familiares, "self".

En este marco general, se evidencian tres tendencias contemporáneas en el estudio científico de la familia:

- Familia como interacción: introduce nociones como microsocial e interaccionista, que sustentan las teorías del conflicto y del intercambio y el Interaccionismo simbólico.

- Familia como sistema: bajo el holismo, se consolidan las teorías del Desarrollo Familiar, General de los Sistemas y Ecología del Desarrollo Humano. 
- Familia como Construcción social: en la era pospositivista, emergen la Etnometodología y los enfoques feministas, que en su evolución se constituyen en teorías de género y en un cambio de paradigma que articula la relación dialéctica entre Familia y Género.

Todos los anteriores bajo los paradigmas: positivistas de la racionalidad instrumental o técnico, interpretativo y crítico. Destacamos su importancia en el tema central de estas líneas y por proponer, posturas innovadoras e integrales de las relaciones humanas, el modelo Crítico, caracterizado por una racionalidad hermenéutica-intrerpretativa y la racionalidad emancipadora o crítica, expuesta en la Fenomenología: Husserl, Schutz, la sociología comprensiva con Weber como el principal exponente y la etnometodología, liderada por Garfinkel, como una variante del interaccionismo.

La esencia del pensamiento crítico, es considerar la realidad como una actividad reflexiva e interactiva, construida socialmente, incluir las facetas del mundo la vida cotidiana, los aspectos, las imágenes y las vivencias de la vida familiar y como lo experimentan sus miembros. Hace parte del Postpositivismo, al igual que El Discurso familiar, que remite tanto a la familia, como a las realidades familiares. Los Enfoques feministas, en su rechazo al positivismo, proponen la noción del género como principio de la organización social, y desde política y ética. La Construcción social de la familia y el género, revocando la cultura judeo-cristiana que preconizaba arquetipos únicos y deterministas del ser hombre o mujer. De ello se desprenden las concepciones modernas que sustentan la Familia:

- Teoría General de Sistemas: la familia como sistema social. Principio de la biología, todos los seres vivos están interconectados.

- Constructivismo social: no hay una realidad sino múltiples realidades. El conocimiento se construye a partir de las interacciones lingüísticas y sociales. 
- Teoría de la comunicación: es imposible no comunicarnos. La comunicación es una relación y un proceso circular

- Teorías de la complejidad: el todo está en las partes y las partes en el todo. Principios hologramático, dialógico y recursividad.

- Cibernética: ciencia del control y de la comunicación en los sistemas humanos, animales y las máquinas.

Este abanico de teorías y conceptos, aporta varias opciones para comprender la Familia contemporánea, incluyendo en su comprensión integral, diversidad de elementos:

Institución social: núcleo de la sociedad, plasmado en las regulaciones constitucionales y legales.

Grupo: con características innatas de ser el grupo primario por excelencia: natural, cohesión, intimidad, convivencia.

Red relacional o de interacciones: foco de la intersubjetividad, prioridad de las relaciones intrafamiliares y la construcción de la identidad.

Antropología: el parentesco, ya sea por consanguinidad, afinidad o civil, que establece sistemas de parentesco propios de cada cultura.

Sistema Social: el mas representativo de los sistemas humanos, conformado por los subsistemas parento-filial (padres e hijos), conyugal (pareja en matrimonio u unión libre) y fraternal (hermanos). Interacciona de manera circular y ecosistémica con el suprasistema o sistema mayor.

En razón de todo lo susodicho, la postura acorde con lo ya expuesto y con la naturaleza necesariamente multidisciplinaria y polivalente de la familia, es asumir los nuevos postulados de la Convergencia y entender la familia y sus integrantes, de una manera sistémica y relacional, que convoque a todas las áreas del conocimiento para su análisis y abordaje tanto en contextos no clínicos (orientación, recepción, evaluación, promoción, prevención, educación), como en contextos clínicos (terapia familiar). 


\section{Enlaces socio-jurídicos}

En la búsqueda de caminos alternativos al orden establecido, es menester asumir formas novedosas de abordar la compleja realidad que presenta hoy la dinámica familiar, contemplando la complementariedad de enfoques (jurídico, psicológico, social), que convoca para su comprensión a múltiples miradas. Ello se plasma en la noción de la: Concepción bio-sico-social-jurídicaespiritual del universo, y exige que desde la formación universitaria del pregrado, se diseñen estrategias cognitivas y didácticas para que los profesionales y funcionarios competentes, maniobren entre diferentes contextos, en la incertidumbre y en la complejidad propias del tercer milenio.

Para ello es necesario una formación técnico instrumental, que favorezca:

- Una visión sociopolítica capacidad crítica y propositiva para interpretar nuestra época y la dinámica de las relaciones económico-sociales;

- Una visión ética para ser consecuentes con la búsqueda de las transformaciones necesarias para armonizar la subjetividad y la objetividad, la individualidad y la colectividad, la heterogeneidad y la homogeneidad,

- Habilidad para construir consensos y disensos en un ambiente de respeto a la expresión del pensamiento.

- Capacidad del operador de ayuda, para comprender tanto sus procesos personales como profesionales, adquirir una fundamentación teórica-metodológica, sólida, moderna, coherente y realizar un trabajo permanente sobre su familia de origen y/o actual forma de convivencia, con el fin de reconocer sus debilidades y fortalezas en el abordaje sociofamiliar. 
Las transformaciones paradigmáticas de finales del siglo, apoyadas en la sistémica, el pensamiento complejo y el holismo, redimensionan la interdisciplinariedad y el estudio integral de la complejidad humana. Esto exige a los profesionales que laboran por el bienestar humano, superar y trascender los métodos tradicionales de conocimiento y análisis de la realidad, articulándose a propuestas globali: ntes, holísticas que permitan un abordaje e intervención in :rdisciplinaria, interinstitucional e intersectorial. Grün (2000) indica:

En el caso del derecho que siempre suele ir a la zaga de los fenómenos económicos y sociales puede decirse que recién nos encontramos en los prolegómenos de este proceso de globalización, producto de la transformación de la sociedad. .....que también en el ámbito de las ciencias jurídicas las modificaciones del contexto, del entorno de los fenómenos jurídicos, que son la economía, la política, entre otros sistemas, han de llevar, ineludiblemente a sustanciales modificaciones en el modo de pensar y crear el derecho. Ello apunta la visión sistémica y cibernética de los fenómenos jurídicos.

Para poder avizorar lo que pueda llegar a ser el derecho del futuro, en una sociedad mundial, globalizada, y para poder contribuir a su construcción, es necesario que lo repensemos a la luz de las nociones sistémicas y especialmente de los aportes de las nuevas disciplinas relacionadas con la complejidad y que reflexionemos sobre la ciencia que lo estudia, y enfoquemos la práctica que lo efectiviza, no en función de que se trata de un fenómeno inmutable a través de los siglos (la idea de que el derecho civil actual es, intrínsecamente semejante a, por ejemplo, el derecho romano), sino como algo, que se ha ido transformando bajo el embate de sucesivas crisis y que, al menos en nuestra época se configura como un sistema de elementos complejos, en interacción dinámica, metaestable y aun inestable, que debe ser modelizado tomando en cuenta estas características para poder entenderlo y (si ello es posible) manejarlo racionalmente. 
Uno de los ejemplos más contundentes, de esta propuesta de colaboración entre las disciplinas sociales y jurídicas, es la de asumir visiones del mundo incluyentes e integradoras es la categoría de las Formas Alternativas de enfrentar los conflictos sociofamiliares, Mediación y Conciliación, como las mas representativas para la ciudadanía, donde necesariamente en los procesos de modernización del estado están comprometidas todas las áreas del conocimiento. Tal como lo ilustra una de las teóricas más significativas en el campo, Sara Cobb:

Dada la complejidad de la vida en los albores del siglo $X X I$, tenemos que orientarnos hacia nuevas teorías de conflicto que no estén constreñidas por el positivismo lógico sino que sean sensibles al contexto, a la interacción, a la cultura, al poder y al discurso.

Es allí en la noción consuetudinaria a la condición humana, del conflicto, como elemento propio de la vida social, que es perentorio efectuar cambios de segundo orden que comprometan las estructuras tradicionales de regulación de los conflictos, facilitando la creación de nuevas esferas de regulación y de otras instituciones mediadoras entre el Estado y los ciudadanos, comprometiendo los procesos de participación ciudadana y comunitaria y la autogestión que representa la capacidad de enfrentar y decidir sobre los conflictos y crisis propias de todos los sistemas humanos. Esto es la innovación y cocreación entre las diferentes áreas del conocimiento, que sin abandonar el rigor científico, incorporan otras nociones para estudiar, evaluar e intervenir la complejidad de los dilemas humanos propios del tercer milenio.

Otro elemento básico en las transformaciones socio-jurídicas, está dado al asumir las nociones emergentes en la perspectiva y equidad de género, que contemple la diferencia inevitable entre el ser hombre y ser mujer y el derecho a que cada persona, decida y asuma su opción e identidad de género, tanto en la dimensión tradicional, conservadora, propia del modelo patriarcal, sin por ello sentir culpa o vergüenza o en la perspectiva moderna, de la 
igualdad, de la simetría en las relaciones familiares y sociales. En todo caso ambas son opciones que están determinadas por el modelo de socialización familiar y por la cultura, pero, que en gran medida dependen del grado de autonomía y madurez para asumir un proyecto de vida individual, familiar o comunitaria. Las nuevas organizaciones familiares y de relaciones de parejas, instauran otras dinámicas y ejercicio de la individualidad, la conyugalidad y la parentalidad, que deben ser asimiladas y legisladas, acordes con los mandatos internacionales y los Derechos Humanos universales.

Los tres ejes centrales atribuidos por la cultura judeo-cristiana a la familia: sexualidad, procreación y convivencia, han variado significativamente como producto de las condiciones concretas y de la significación que para los sujetos adquieren las relaciones familiares en las actuales condiciones. Ya la conyugalidad, la parentalidad y la procreación, no son los vértices de las uniones de las parejas, ni de la cohabitación y los avances científicos, tecnológicos y genéticos evidencian categorías e interacciones propias del tercer milenio, que coexisten con las formas tradicionales de concebir y vivir la familia, el matrimonio y la afectividad.

La tendencia a defender nuevas formas de familia, como la que se originaría de uniones entre homosexuales (por ahora, normalmente limitadas al número de dos personas del mismo sexo) muestra un cambio de mentalidad en la que pierde valor la noción tradicional de familia. En esta mentalidad se asumen nuevos principios reguladores para la vida social, especialmente por lo que se refiere a la relación entre adultos y niños (Mujer Nueva, 2006).

En eventos específicos como las rupturas de pareja, el cambio es contundente, al considerar que ya no es un fenómeno aislado, negativo, sino que evoluciona a la noción de la organización de la familia en el post-divorcio y los nuevos enfoques se centran en la adaptación y flexibilidad presente y futura del sistema familiar, para superar la crisis inherente y la asunción de los roles parento-filiales, cuando ya se disuelve 
el vinculo conyugal. De esta manera el divorcio o la separación, en sí mismos no son disfuncionales o negativos, sino la evidencia de las mudanzas estructurales en las relaciones erótico-afectivas. Todo ello se evidencia en las modificaciones de las Constituciones, de la legislación y de las políticas públicas que inevitablemente deben acoger las transformaciones sociales, económicas, geopolíticas y culturales, para garantizar un desarrollo sustentable, equitativo y flexible al Cambio de la época.

La modernización de los estados y los movimientos sociales, que expresan formas participativas y autónomas de la ciudadanía y de la multiculturalidad del planeta, facilitan dichas transformaciones en procesos dinámicos, flexibles, tolerantes, que comprometen particularmente a los profesionales de las ciencias sociales y humanas, en acciones interdisciplinarias, intersectoriales e interinstitucionales.

Mas allá del compromiso disciplinar, es una condición ineludible como ciudadanos del mundo, con derechos, pero también con deberes en todos los contextos de la interacción humana. 


\section{Referencias}

CEPAL-Naciones Unidas. (1997). La brecha de la equidad, América Latina. El Caribe y la cumbre social. Santiago de Chile: Naciones Unidas.

Comité Interinstitucional de Familia, CIF, Alcaldía de Medellín (1999). Familia Siglo XXI, Sistematización del Proyecto. Medellín: Editorial Marín Vieco.

Departamento Nacional de Planeación, Instituto Colombiano de Bienestar Familiar - Misión Social (2002). Familias colombianas: Estrategias frente al riesgo. Santafé de Bogotá: Gente nueva.

Gracía Fuster, Erique y Musiti Ohoa, Gonzalo (1999). Psicología social de la familia. Barcelona: Paidós.

Grün, Ernesto (2000). La Globalización del derecho: Un fenómeno sistémico y cibernético. www. La globalización del derecho un fenómeno sistémico y cibernético.htm (consultado Julio, 2006)

Memorias (2002). Primer Congreso Internacional Derecho de Familia, Universidad de Antioquia. Medellín: Facultad de Derecho y Ciencias Políticas. Universidad de Antioquia. (CD).

Memorias (2004). Segundo Congreso Internacional Derecho de Familia, Universidad de Antioquia. Medellín: Facultad de Derecho y Ciencias Políticas. Universidad de Antioquia. (CD).

Memorias (2006). Tercer Congreso Internacional Derecho de Familia, Universidad de Antioquia. Medellín: Facultad de Derecho y Ciencias Políticas. Universidad de Antioquia. (CD). 
Memorias (2004). Congreso Internacional Justicia Alternativa. Cali: Universidad de San Buenaventura. Cali. (CD).

Mujer Nueva (2006). México (Consultada agosto 2006 de http://www.mujernueva.org/articulos/articulo. México.

Quintero Velásquez, Angela María (2004). Diversidad familiar en el tercer milenio. Agora, 4. Medellín: Universidad San Buenaventura, Formación Humana y Bioética.

Quintero Velásquez, Angela María (2001). Tesauro Colombiano en Familia y Género. Medellín: Centro de Investigaciones Sociales y Humanas-CIHS. Universidad de Antioquia, Fundación para el Bienestar Humano. Digital Express.

Quintero Velásquez, Angela María. (1995). Consideraciones acerca del trabajo interdisciplinario. Prospectiva, 2. Santiago de Cali: Escuela de Trabajo Social y Desarrollo Humano, Facultad de Humanidades. Universidad del Valle. 